\title{
Ocorrência e morfologia de glândulas nas pernas de Centris e Epicharis (Hymenoptera, Anthophoridae)
}

\author{
Aldirene Costa Franco ${ }^{1,2}$ \\ Carminda da Cruz-Landim ${ }^{1}$
}

\begin{abstract}
Occurrence and morphology of glands in legs of Centris and Epicharis (Hymenoptera, Anthophoridae). The presence of glands in insect legs is largely difunded. In bees they are present in solitary and social species. In Centris and Epicharis three different types of glandular structures were found: bag-shaped structures in males femur and tibia, unicelular glandular cells in all segments of all leg pairs in males and females, but more developed in females, and differentiated epidermis in the basitarsus of both sexes. The tarsal gland present in the distal tarsomere of all legs of males and females are a special type of the bag-shaped structure. The nature of secretion and it use is unknow, but some morphological and stainning properties indicate a lipidic nature.
\end{abstract}

KEY WORDS. Hymenoptera, Anthophoridae, bee, glands, legs, secretion

De um modo geral, todos os insetos apresentam glândulas em seus apêndices locomotores. Nas abelhas foi descrita a presença de estruturas glandulares tarsais em Apis mellifera Linnaeus, 1758, alguns Meliponinae e Bombus (ARNHART 1923; Chauvin 1960; Cruz-Landim \& CUnha 1965; Lensky et al. 1984; Pouvreau 1991; Cruz-Landim \& Silva DE Moraes 1994) e também em todos os outros artículos das pernas dos Meliponinae (PATrício \& Silva DE Moraes 1995; CRUZ-LANDim et al. 1998).

Em machos de Centris Lepeletier, 1824 foram descritas estruturas saculiformes interpretadas como glândulas, no fêmur, nas tíbias e no último segmento tarsal do par posterior de pernas (STORT \& CRUZ-LANDIM 1965). WITTMANN \& BLOCHTEIN (1995) verificaram que os machos dessas abelhas seguram as antenas das fêmeas com as pernas, durante o acasalamento, o que sugere a possibilidade de substâncias feromonais aí produzidas serem percebidas pelas fêmeas, com esse comportamento.

Estruturas saculiformes no interior das tíbias também foram encontradas em rainhas de Meliponinae (CRUZ-LANDiM et al. 1998) e em fêmeas de Oxaea flavescens Klug.

No entanto, estas estruturas não estão restritas às abelhas. BILLEN (1984) encontrou uma estrutura saculiforme com características glandulares em operárias de Crematogaster scutellaris Olivier, 1792 (Formicidae) e BROUSSE-GAURY (1983) descreveu estruturas semelhantes em Forficula auricularia Linnaeus e Labidura

1) Departamento de Biologia, Instituto de Biociências, Universidade Estadual Paulista. Caixa Postal 199, 13506-900 Rio Claro, São Paulo, Brasil.

E-mail: cclandim@rc.unesp.br

2) Bolsista de Iniciação Científica PIBIC/CNPq/Unesp. 
riparia Pallas. Em todos estes casos a estrutura saculiforme estava associada a um tendão muscular, no interior do segmento.

As abelhas da tribo Centridini são coletoras de óleos (VoGEL 1974) e para esta coleta utilizam estruturas presentes nas pernas. As fêmeas dessas abelhas possuem nas superfícies internas dos basitarsos das pernas anteriores e médias, pentes de cerdas rígidas alargadas no ápice (VogEL 1974; NEFF \& SIMPSON 1981), com as quais raspam o cálice floral para a coleta de óleo (VOGEL 1974; RÊGO \& AlbuQuerque 1989; SAZIMA \& SAZIMA 1989).

Os óleos coletados são substâncias produzidas e armazenadas em nectários modificados denominados elaióforos presentes em certas famílias de plantas (HILLER \& WITTMANN 1994).

Em um estudo realizado por PEDRo (1994), verificou-se que as flores de Malpighiaceae são as preferidas pelos Centridini para coleta de óleo. Entretanto, apesar do conhecimento deste comportamento dos Centridini e de outras abelhas, não há indicações seguras de como esses óleos seriam transportados para a colônia e de seu uso posterior, sugerindo-se que possam servir como alimento.

Neste trabalho relata-se a ocorrência de estruturas presentes nas pernas das fêmeas e dos machos de Epicharis Lepeletier, 1841 e Centris, cuja função é discutida em relação ao que acaba de ser exposto.

\section{MATERIAL E MÉTODOS}

Para a realização desse estudo, foram utilizados espécimens das seguintes espécies, todos coletados em flores, no Campus da Universidade Estadual Paulista, Rio Claro, São Paulo: Centris (Centris) varia (Erichson, 1848) (oito fêmeas e seis machos); Centris fuscata Lepeletier, 1841 (seis fêmeas e dez machos); Epicharis rústica flava (Friese, 1900) (doze fêmeas e dez machos).

A fixação das pernas foi feita em paraformaldeído a $4 \%$ em tampão fosfato de $\mathrm{Na}$ a $\mathrm{pH} 7,0$. Os diferentes pares de pernas foram fixados separadamente e em alguns casos também os artículos de cada perna. Para facilitar a penetração do fixador foi aplicado choque térmico colocando-se as peças, já no fixador, em forno de micro-ondas por cinco a sete segundos. As peças permaneceram no fixador, por pelo menos 48 horas.

Para microscopia óptica, após a fixação, o material foi embebido em resina (Metacrilato, JB4 ou JB4 plus). As peças foram deixadas na resina de embebição pelo menos 48 horas com passagem pelo forno de micro-ondas depois de 24 horas. A inclusão deu-se na mesma resina. Os cortes do material foram feitos em micrótomo para historesina com a espessura de $7 \mu \mathrm{m}$. A coloração do material, já montado em lâminas, foi feita com hematoxilina e eosina, ácido periódico-Schiff(PAS), azul de bromofenol e azul de toluidina. Foram realizados também estudos da superfície externa das pernas com microscopia eletrônica de varredura (MEV). As pernas foram preparadas inteiras ou separadas conforme os artículos. As peças desidratadas foram secadas ao ponto crítico para retirada total dos líquidos, recobertas com ouro, examinadas e fotografadas ao microscópio eletrônico de varredura, em vistas dorsal e ventral. 


\section{RESULTADOS E DISCUSSÃO}

Os resultados gerais do estudo realizado estão expressos na tabela I.

Tabela I. Ocorrência e morfologia das estruturas presentes nos vários segmentos das pernas de machos e fêmeas de Centridini. (X) Ausente, (1) glândula unicelular, (2) estrutura saculiforme, (3) epiderme desenvolvida ou modificada, (4) desembocadura de glândulas, ( $T$ ) glândula tarsal.

\begin{tabular}{|c|c|c|c|c|c|c|c|c|}
\hline \multirow{2}{*}{ Espécies } & \multirow{2}{*}{ Sexo } & \multirow{2}{*}{ Coxa } & \multirow{2}{*}{ Trocanter } & \multirow{2}{*}{ Fêmur } & \multirow{2}{*}{ Tibia } & \multirow{2}{*}{ Basitarso } & \multicolumn{2}{|c|}{ Tarsômeros } \\
\hline & & & & & & & Intercalares & Distal \\
\hline \multirow[t]{2}{*}{ Epicharis rustica flava } & Macho & $\mathrm{x}$ & 1 & 1 e 2 & $1 \mathrm{e} 2$ & 3 & $x$ & $T$ \\
\hline & Fêmea & 4 & 4 & 1 & 1 & 3 & $x$ & $T$ \\
\hline \multirow[t]{2}{*}{ Centris fuscata } & Macho & $x$ & 1 & 1 e 2 & 1 e 2 & 3 & $\mathrm{x}$ & $T$ \\
\hline & Fêmea & $x$ & 1 & 1 & 1 & 3 & $\mathrm{x}$ & $\mathrm{T}$ \\
\hline \multirow[t]{2}{*}{ Centris (Centris) varia } & Macho & $x$ & 1 & 1 e 2 & 1 e 2 & 3 & $\mathrm{x}$ & $\mathrm{T}$ \\
\hline & Fêmea & $x$ & 1 & 1 & 1 & 3 & $x$ & $T$ \\
\hline
\end{tabular}

(X) Ausente, (1) glândula unicelular, (2) estrutura saculiforme, (3) epiderme desenvolvida ou modificada, (4) desembocadura de glândulas, $(T)$ glândula tarsal.

Foram encontrados três tipos de estruturas nas pernas das espécies estudadas: estruturas saculiformes, células glandulares isoladas e epiderme diferenciada, além das glândulas tarsais, presentes nos pre-tarsos. Não houve variação na organização celular e na reação às colorações empregadas entre as espécies. Portanto, a descrição a seguir aplica-se a todas elas e as ilustrações, embora pertençam a exemplares de uma ou outra espécie, servem para todas.

Estruturas saculiformes são formadas por um epitélio limitando um lumen alargado e irregular no interior do artículo formando um saco de paredes enrugadas (Fig. 1A,B,C). As células desse epitélio são prismáticas ou cúbicas com núcleos basais. Estas células às vezes apresentam-se vacuolizadas (Fig. 1C). Essa estrutura é característica dos machos das espécies de abelhas estudadas e está localizada no fêmur e na tíbia dos três pares de pernas, com diferentes graus de desenvolvimento. É maior no terceiro par de pernas, média no segundo e pequena no primeiro par.

STORT \& CRUZ-Landim (1965) estudando Centris tarsata Smith, 1874, C. fuscata, C. vittata Lepeletier, 1841, C. violacens, Epicharis rustica flava e Xylocopa hirsutissima Maidl, 1912, não encontraram essas estruturas nas duas últimas espécies. Quanto às espécies de Centris, só as encontraram nos machos, como no presente trabalho.

Embora no presente trabalho isto não fique claro, em Meliponinae CRUZLANDIM et al. (1998) verificaram o desenvolvimento deste saco a partir de dobra da epiderme que reveste os tendões musculares dos artículos em que está presente.

Estruturas saculiformes foram observadas nas tíbias dos machos de abelhas da sub-família Euglossinae (VogEL 1963, 1974), igualmente especializadas na coleta de óleos florais, onde constituem um órgão tibial (CRUZ-LANDIM et al. 1965) mas aparentemente não se trata de estruturas homólogas, visto que sua organização é completamente diferente.

Apesar da designação de "glândula" atribuída aqui a estas estruturas, elas parecem ser basicamente uma estrutura armazenadora de substâncias, mas a natureza e origem das substâncias armazenadas é desconhecida visto que são as fềmeas destas espécies que coletam óleo, e não os machos (PEDRo 1994). 


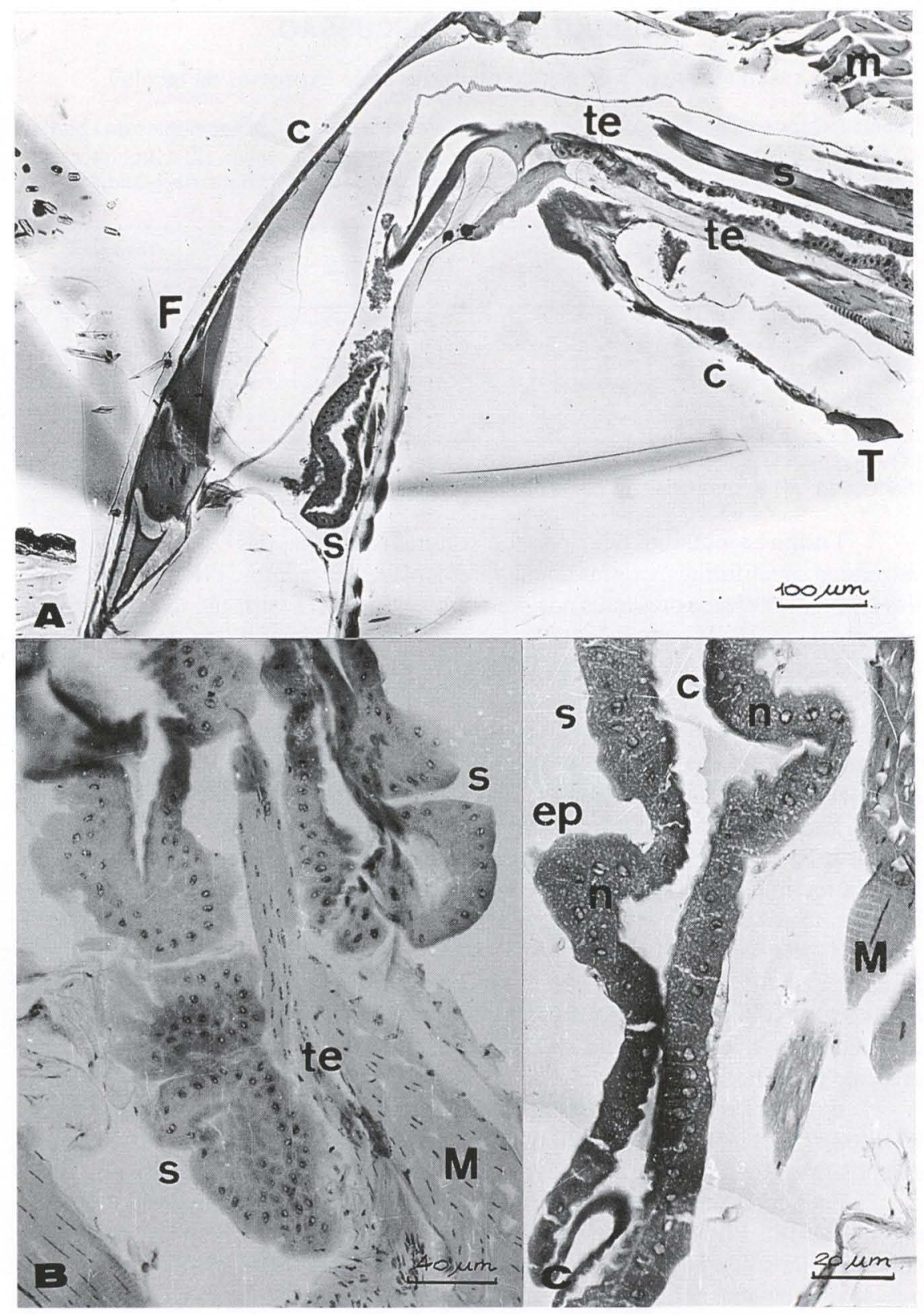

Fig. 1. Estrutura saculiforme (s) da tíbia ( $T$ ) e fêmur ( $F)$ de Centris e Epicharis. (A) Aspecto geral do saco (s) no interior do fêmur e da tíbia (Epicharis, segundo par de pernas); $(B, C)$ epitélio convoluto de células prismáticas ou cúbicas da parede dos sacos (s) no fêmur do segundo $(B)$ e terceiro $(C)$ pares de pernas de Epicharis. (te) Tendão muscular, (M) músculos, (c) cutícula tegumentar. 


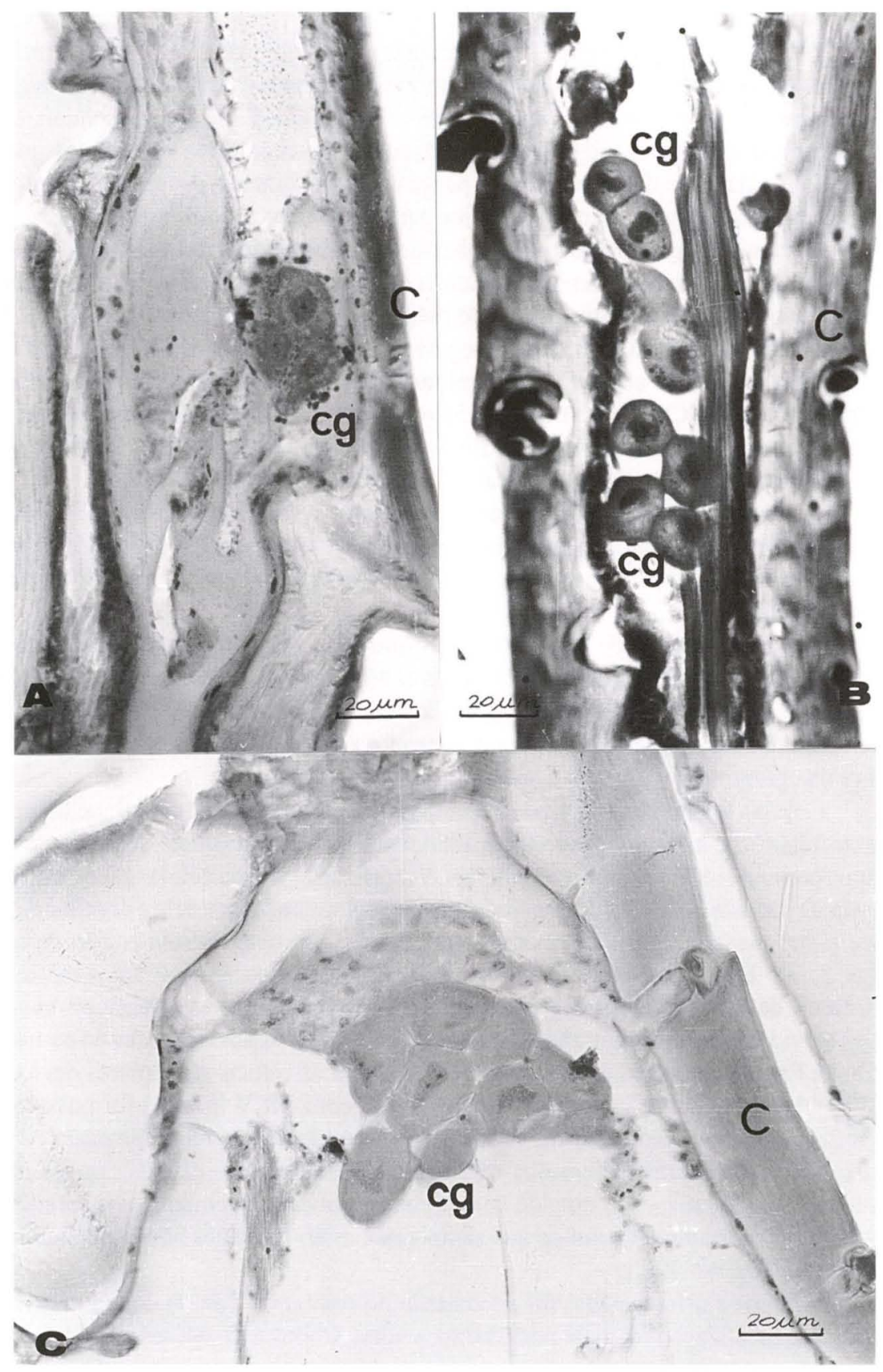

Fig. 2. Células glandulares $(\mathrm{cg})$ presentes nas fêmeas e nos machos de Centris e Epicharis, aparecendo sozinhas ou em grupos de poucas células. (A) Fêmur de Centris; (B) tíbia de Centris; (C) tíbia de Epicharis; (C) tegumento. 
BILLEN (1984) encontrou, em formigas, indicações de que o epitélio que reveste o saco é secretor. Nas abelhas em estudo, a presença de vacúolos nas células poderia também ser tomada como indicativa de atividade secretora celular. $\mathrm{O}$ material produzido seria inicialmente armazenado no citoplasma das células que formam a sua parede e depois eliminado para a luz, onde ficaria depositado, portanto, a natureza das estruturas saculiformes fica para ser esclarecida posteriormente.

O caminho percorrido pelas substâncias armazenadas no interior dessas estruturas, e sua utilização também continua obscuro, visto que não foi encontrada ligação com o exterior, ou qualquer duto para sua liberação. Para formigas BILLEN (1984) verificou a abertura do saco na região pré-tarsal da tíbia e BROUSSE-GAURY (1983) localizou uma abertura na membrana que liga o pré-tarso ao tarsômero seguinte. STORT \& CRUZ-LANDIM (1965) verificaram a existência um ducto interconectando as estruturas do fêmur e tíbia e outro que atravessaria os tarsômeros terminando no tarsômero distal ventralmente, na base do arólio.

A ocorrência dessas estruturas saculiformes exclusivamente em machos, como verificado aqui, não é geral. Em Meliponinae, CRUZ-LANDIM et al. (1998) as encontraram em operárias e rainhas e BILLEN (1984) também as encontrou em fêmeas de formigas.

Um tipo especial de estrutura saculiforme é a glândula tarsal descrita por ARNHART (1923) e CRUZ-LANDIM \& CUNHA (1965) encontrada em todas as abelhas já examinadas (Tab. I), localiza-se no pré-tarso de todos os pares de pernas. Tem a forma de um saco, com abertura para o exterior na base do arólio, e resulta de uma dobra da epiderme que reveste $o$ artículo para o seu interior.

Células Glandulares Isoladas: são esféricas com canalículos intracelulares que se ligam a canalículos excretores individuais. Podem aparecer sozinhas, em grupos com poucas ou numerosas células. A localização dessas células glandulares é bastante variada podendo estarem próximas ao tegumento do artículo e distribuídas entre a sua musculatura ou formando aglomerados em determinada região deste (Figs 2,3). Estão presentes tanto nos machos como nas fêmeas das espécies estudadas de Centris e Epicharis sendo que nas fêmeas apresentaram-se mais desenvolvidas e foram encontradas na maioria dos artículos dos três pares de pernas (Tab. I). Em alguns casos não foi possível visualizar as células glandulares devido à dificuldade de fixar e cortar este material, mas com MEV (Fig. 4) foi possível visualizar orifícios circulares na cutícula correspondentes a sua localização. Os orifícios são a desembocadura dos canalículos excretores das células através da cutícula e sua localização coincide com a das glândulas unicelulares nos estudos histológicos, portanto, conclui-se que sempre que estão presentes há uma glândula subjacente (Fig. 4A,B,C).

Epiderme diferenciada: foi encontrada no basitarso (Tab. I) com a mesma estrutura e localização relatada por CRUZ-LANDIM \& SILVA DE MORAES (1994).

No que diz respeito às reações histoquímicas, as glândulas unicelulares e as epiteliais apresentam baixa basofilia conforme evidenciado pela coloração com hematoxilina e azul de toluidina. A acidofilia é mediana como mostra o resultado da coloração com eosina. De uma maneira geral, todas as glândulas coraram-se 



Fig. 3. Diferentes localizaçōes das céluias glandulares $(\mathrm{cg})$ no interior dos segmentos. (A) Células isoladas $(\mathrm{cg})$ distribuídas ao longo da face interna do tegumento da tíbia; (B) células isoladas (cg) distribuídas entre a musculatura do fêmur; $(C)$ aglomerado de células glandulares (cg) na região apical do fêmur de Epicharis. As setas indicam os canalículos intracelulares; (e) tegumento. 


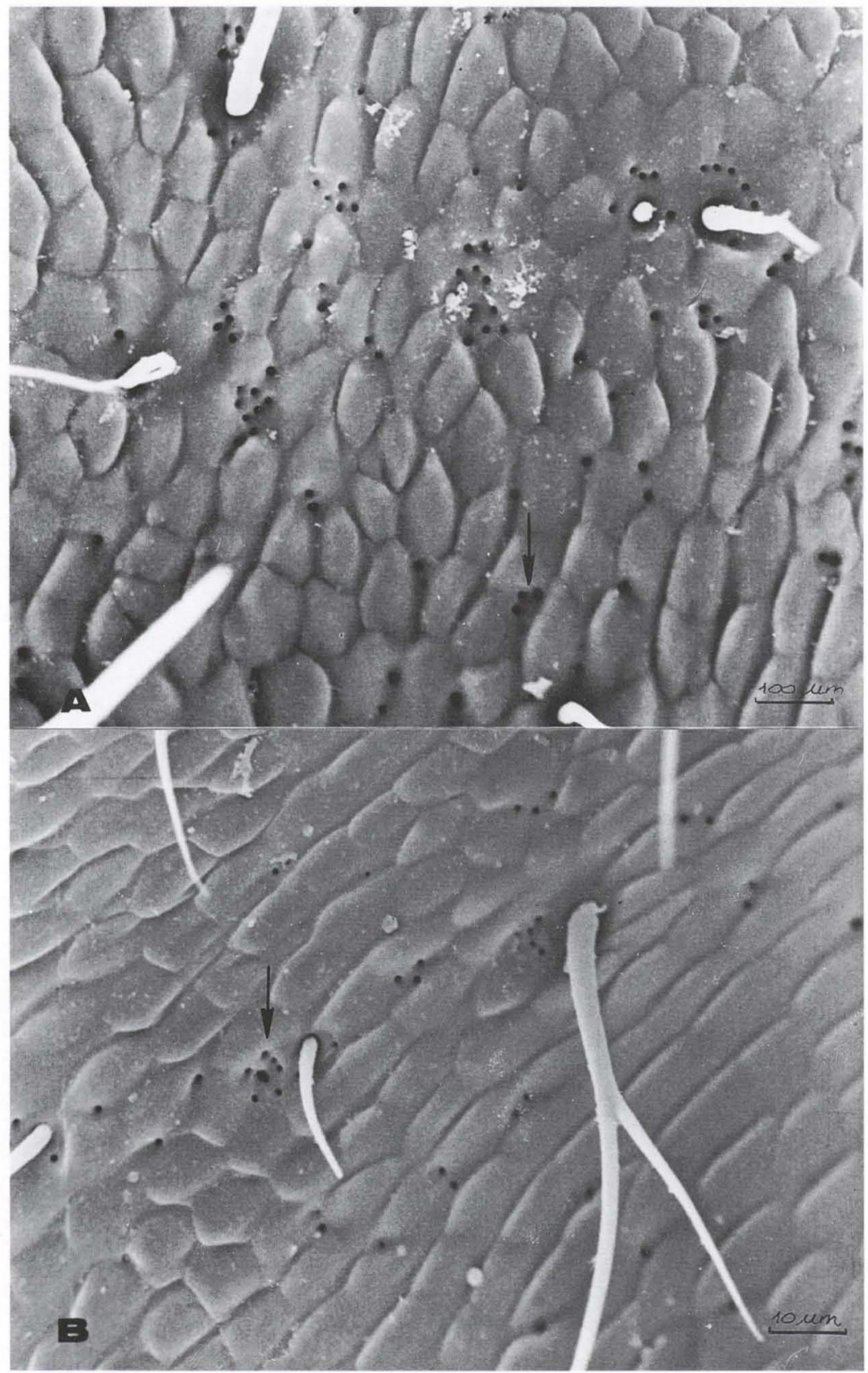

Fig. 4. Microscopia eletrônica de varredura destacando os orifícios que correspondem à desembocadura das células glandulares. (A) Orifícios na tíbia do segundo par de pernas de fêmeas de Epicharis; (B) fêmur do segundo par de pernas de Epicharis.

Revta bras. Zool. 16 (Supl. 2): 1 - 10, 1999 
fracamente pelo PAS, sendo que só os canalículos intracelulares ficam destacados. A coloração com azul de bromofenol foi também fraca. Estes resultados indicam composição não proteica para a secreção, tanto das estruturas saculiformes, como das células glandulares unicelulares, como da glândula tarsal e epiderme do basitarso. A vacuolização das células das estruturas saculiformes também é compatível com secreção não proteica e indicativa de natureza lipídica.

A presença dos tipos glandulares descritos é generalizada nos insetos, tendo sido encontrada em outras abelhas e em outros insetos sociais (H.X. Soares comunicação pessoal) e não sociais. Portanto, embora a ocorrência de dimorfismo sexual nas abelhas estudadas indique papéis especiais ligados ao comportamento dos sexos, esta condição deve constituir-se em caráter derivado, sendo provavelmente a condição inicial a de ocorrência generalizada destas estruturas em todos os insetos independente de sexo ou das castas no caso dos sociais.

AGRADECIMENTOS Este trabalho teve financiamento da FAPESP e CNPq.

\section{BIBLIOGRAFIA}

ARnhart, L. 1923. Das Krallenglied der Honigbiene. Arch. Bienenk. 5: 37-86.

BILLEN, J.P.J. 1984. Morphology of tibial gland in the ant Crematogaster scutellaris. Naturwiss. 77: 234-235.

Brousse-Gaury, P. 1983. Sur l'existence d'une glande tibiale chez Lapidura riparia Pallas et Forficula auricularia L. (Insectes, Dermapteres). C.R. Acad. Sci., Ser. III, Paris, 297: 203-208.

Chauvin, R. 1960. Les substances actives sur le comportement à l'interier de la ruche. Ann. Abeille 3: 185-197.

Cruz-Landim, C.; A.C. STort; M.A.C. CruZ \& E.W. Kitajima. 1965. Órgão tibial dos machos de Euglossini. Estudo ao microscópio óptico e eletrônico. Rev. Brasil. Biol. 25 (4): 323-342.

Cruz-Landim, C. \& M.A.S. CunHa. 1965. Glande tarsale des abeille sans aiguillon, p.219-225. In: P.P. GRASSÉ \& M. LÜSCHER (Ed.). Comptes Rendus du Ve Congresse de l'Union Internationale pour l'Etude des Insectes Sociaux. Toulouse, 309p.

CRUZ-LANDim, C. \& R.L.M. Silva DE Moraes. 1994. Ultrastructural Localization of New Exocrine Glands in Legs of social Apidae (Hymenoptera) Workes. Jour. Adv. Zool. 15 (2): 6.0-67.

Cruz-Landim, C.; R.L.M. Silva De Moraes; H.C. Salles \& R.D. Reginato. 1998. Note on glands present in Meliponinae (Hymenoptera: Apidae) Bee Legs. Revta bras. Zool. 15 (1): 159-165.

HiLLER, B. \& D. WiTTMAN. 1994. Seasonality, nesting biology and mating behavior of the oil-collecting bee Epicharis dejeanii (Anthophoridae, Centridini). Biociências, Porto Alegre, 2 (1): 1-192.

Lensky, Y; P. Cassier; A. Finkel; A. Teeslshee; R. Shelensinger; C. Delome JOULIE \& N. LEVINSOHN. 1984. Le glandes tarsales de l'abeille mellifique (Apis mellifera L.): reines, ouvriéres et faux bourdons (Hymenoptera, Apidae). II. Role biologique. Ann. Sci. Nat. Zool. Biol. Anim. 6: 167-175. 
NEFF, J.I. \& B.B. Simpson. 1981. Oil-collecting strutures in the Anthophoridae (Hymenoptera): morphology, function and use in systematics. Jour. Kansas Entomol. Soc. 54 (1): 95-123.

Patrício, E.F.L.R.A. \& R.L.M. Silva DE Moraes. 1995. Do the workers of the stingless bees Frieseomelitta silvestri and $F$. varia (Apidae, Trigonini) use their legs only for walking? Acta Microscopica, Rio de Janeiro, 4 (Suppl. A): 162. PEDRO, S.R.M. 1994. Interações entre abelhas e flores em uma área de cerrado no NE do Estado de São Paulo: Abelhas coletoras de óleo (Hymenoptera: Apoidea: Apidae). Anais Encontro Sobre Abelhas, Ribeirão Preto, 1: 243.

PouvreAU, A. 1991. Morphology and histology of tarsal glands in bumble bees of the genera Bombus Pyrobombus and Megabombus. Can. Jour. Zool. 69: 866-872.

RÊGO, M.M.C. \& P.M.C. AlbuQuerque. 1989. Comportamento das abelhas visitantes de murici, Byrsonima crassi folia (L.) Kunth, Malpighiacea. Bol. Mus. Par. Emilio Goeldi, sér. Zool., 5 (2): 179-193.

SAZIMA, M. \& I. SAZIMA. 1989. Oil-Gathering bees visiting flowers of eglandular morphs of the oil-producing Malpighiacea. Botanica Acta 102: 106-111.

STORT, A.C. \& C. CRUZ-LANDIM. 1965. Glândulas dos Apêndices locomotores do gênero Centris (Hymenoptera, Anthophoridae). Bol. Inst. Angola 21: 5-14.

VOGEL, S. 1963. Duftdrüsen im Dienste der Bestäubung: Über Bau und Funktion der Osmophoren. Akad. Wiss. Lit. Abh. Math. Naturwiss. Kl., Mainz, 1962: 599-763.

1974. Ölblumen and ölsammelnde Bienen. Akad. Wiss. Lit. Abh. Math. Naturwiss. Kl. (Mainz). Trop. Subtrop. Pflanz. 7: 1-267.

WitTMAnN, D. \& B. BlockteIN. 1995. Why males of leafcutter bees hold the females antennae with their front legs during mating. Apidologie 26: 181-195.

Recebido em 28.V.1998; aceito em 04.XI.1999. 